\title{
Influence of Cervical Spine Manipulation on Neck Joint Position Sense error in patients with chronic neck pain.
}

\author{
Iã Ferreira Miranda1, Daniel Facchini², Eliane Fátima Manfio³
}

\begin{abstract}
Introduction: Cervical joint dysfunction may interfere with the sensorimotor afferent response, interfering with neck neck Joint Position Sense error (JPS). Objective: The aim of this study was to evaluate the influence of Cervical Spine Manipulation (CSM) on neck JPS error in patients with chronic neck pain. Method: 21 patients with chronic neck pain were divided into 2 groups: Spinal Manipulation Group (MG) or Sham Group (SG) who received 4 sessions of CSM and Sham CSM respectively. JPS was assessed in three different time frames: 1) pre-intervention; 2) Right after the first intervention (post-intervention 1); and 3) After a chronic intervention (post-intervention 2). The outcome measured in this study was the head reposition accuracy test with the Revel's Test. Results: The JPS showed no significant differences between pre- and post-intervention 1 and 2 for any of the assessed groups. Conclusion: We conclude that, for this sample, neither the CSM nor the Sham CSM statistically changed the JPS error for neither groups. We believe that the changes in JPS after CSM were concealed because the ability of other sensory system information to compensate for inadequacies in any other component. Therefore, more studies have to be done with a stronger methodological rigor, clinical prediction rule for spinal manipulation, bigger sample and a blind assessment.
\end{abstract}

Keywords: Kinesthesia. Chiropractic Manipulation. Neck Pain.

\section{INTRODUCTION}

Proprioception is a term invented by Charles Sherrington to indicate the perception of the body's own position due to the receptors in the muscles, joints and skin. ${ }^{(1,2)}$ Furthermore, this body's own perception capacity can be impaired by muscle fatigue, which would be a cause for worsening of motor responses. ${ }^{(3)}$ Additionally, Joint Position Sense, is the ability to reposition a joint actively, and authors consider to be one of the parameters of proprioception. ${ }^{(2)}$ Thus, altered proprioception, postural control and so JPS, increase the possibility of musculoskeletal injuries. ${ }^{(4)}$ In addition, the perception of the head in space demands not only of the vestibular, visual and cerebellar systems, but also of mechanoreceptors from cervical spine, muscles and skin, ${ }^{(5)}$ and they can reorganize the hierarchy of sensory information to maintain the JPS in a variety of environmental conditions. ${ }^{(6)}$

Cervical and lumbar joint dysfunction is one of the major causes of musculoskeletal pain. ${ }^{(7)}$ They are described in the literature, and recent neurophysiological studies have shown that spinal articular facets have both mechanoreceptors and nociceptors and those facets' inflammation lead to a decrease of the threshold of nerve endings. ${ }^{(7)}$ Moreover, neurophysiologic studies have shown that the neck is composed by a great density of muscle spindles. ${ }^{(8)}$ Due to the high density of muscle spindles and the fact that the neck plays an important role in the sensorimotor integration responsible by the neck JPS, ${ }^{(9,10)}$ is not incorrect to affirm that the cervical joint dysfunction, be it traumatic or not, interferes with the sensorimotor afferent response, unsettling neck JPS, postural control and oculomotor control. ${ }^{(10-13)}$ Therefore, restrictions on the neck movements can affect the quality of the neck JPS. ${ }^{(7,14-17)}$ Moreover chronic neck pain has a great socioeconomic impact in the health system, being one of the most common problems treated by chiropractors, also, there is a high likelihood of the individual presenting it during some stage of his life. ${ }^{(18-22)}$

Several studies have been published affirming that joint dysfunction, also called by chiropractors as vertebral subluxation complex, represents an area of altered afferent responses to the central nervous system (CNS), which will lead to an altered somatosensory and motor control response. ${ }^{(7,23,24)}$ Thus, chronic neck pain, has been proposed as an important correlation factor with disturbance in cervical proprioceptive information. ${ }^{(12,25)}$ 
To quantify the neck JPS, the Head Repositioning Accuracy Test (HRA) was used, which would be the ability of repositioning the head in an initial position after an active movement of the head. This test was used in several studies ${ }^{(5,12,15,17,26)}$ and was validated by Roren in 2009. ${ }^{(27)}$

This test was first proposed by Revel, Andre and Minguet ${ }^{(5)}$ and is a test that has good reliability and validity. ${ }^{(26,27)}$ They assessed the absolute error of two tests (HRA and three-dimensional ultrasound motion analysis) for the evaluation of neck kinesthesia and found no significant differences between the tests. ${ }^{(27)}$

Due to abnormal proprioceptive afferent response of sensorimotor control and the cervical disability generated by the various structures of the neck, which increase the likelihood of injury and degenerative joint disease, this study aimed to evaluate the influence of CSM and a Sham CSM in the neck JPS in patients with chronic neck pain.

\section{METHOD}

\section{Ethical aspects}

The study was carried out in the Chiropractic Clinical School of the Feevale University, at Novo Hamburgo, Brazil. Also, this project followed the resolutions of the National Health Council № 466, December 12, 2012, which provides guidelines and standards involving human subjects and was approved by the university's research ethics committee of Feevale University ( $\left.n^{\circ} 555.015\right)$. Furthermore, all participants were informed about the procedures, benefits and risks before being given and signing the written informed consent form.

\section{Participants}

Participants were selected in Feevale university's chiropractic and physiotherapy school clinics and also within the community, which were are indicated by professionals of chiropractic or physiotherapists. This study was conducted with a non-probabilistic sample, attended by 33 subjects. Of these, 6 patients were excluded by the exclusion criteria (see Table 1) and 6 were excluded for not completing the trial period of 4 interventions. Thus, totalizing 21 patients, 3 males and 18 females, who were divided into two groups: MG, consisting of 14 patients with chronic neck pain, aged between 20-59 years, with a mean age of $30.2(S D=11.0)$ years, which received the CSM; and the SG, composed of 7 patients with chronic neck pain, aged between 20-59 years, mean age of $38.9(S D=17.0)$ years, which received the Sham CSM.

\section{Outcome Measures}

Data collection was performed in previously scheduled appointments with patients interested in participating in the project and was divided into three steps: Step 1, consisted of the voluntary acceptance of the participant in the study, assessment to verify the inclusion and exclusion criteria of the
Table 1. Eligibility Criteria

\begin{tabular}{ll}
\hline Inclusion & \multicolumn{1}{c}{ Chronic Neck Pain } \\
\hline & Both genders \\
& Age between 18 and 59 years \\
& NDI $\geq 10 \%$ \\
& Did not receive a cervical spine manipulation in a period of \\
& three months before the research \\
& Signed the Informed consent \\
\hline Exclusion & Vertebrobasilar insufficiency \\
& Aneurism \\
& Bone Cancer \\
& Bone infection \\
& Recent fractures \\
& Vertebral luxation \\
& Any neurological or vestibular diseases \\
High vertebral instability & Spine surgery \\
Whiplash & \\
&
\end{tabular}

study and interview. Step 2 was to assess cervical kinesthesia (pre-intervention), the group allocation, and the intervention of the group, which was in 4 interventions, and cervical kinesthesia reassessment, performed immediately after it (post-intervention 1). Step 3, was on the last intervention, which was evaluated the neck JPS immediately after the last intervention (post-intervention 2). The interventions were provided with a mean interval of 28.5 days for the MG and 30.6 days for the SG, also, all evaluations and interventions were conducted during the 7 months period by the same trained examiner.

\section{Assessment of neck JPS}

To assess the neck JPS the Head Repositioning Accuracy test (HRA) was used, which was originally proposed by Revel, Andre and Minguet ${ }^{(5)}$ and has been widely used in scientific researches. ${ }^{(3,26,28,29)}$ The HRA measures the ability of the neuromusculoskeletal system to reposition the head in a neutral position after active movements in different planes of motion. A deficit in this ability is mainly attributed to an afferent disturbed response of the neck mechanoreceptors. The kinesthetic alteration is measured by the difference between the initial position and the position after the active movement of the individual. ${ }^{(7,12)}$

Participants sat in a chair with low back support with their hands on their thighs, using only light cloths and without the use of accessories (scarf, earrings or hair accessories). The legs were placed in a comfortable angle of $90^{\circ}$ and with the feet to the ground or to a support if they were too short. 
The eyes were blindfolded with the use of a sleep mask and the participant was instructed to remain with closed eyes during the procedure. An elastic band with a fixed laser pointer (Figure $1 \mathrm{~A}$ ) was attached to the head, which was adjusted according to the dimensions of the head of each individual. The position of the laser on the elastic band was calibrated by the investigator at an angle of $90^{\circ}$, parallel to the ground with the use of an inclinometer, toward the center of a portable coordinate system at a distance of $100 \mathrm{~cm}$. This coordinate system has total radius of $20 \mathrm{~cm}$, with a circle for each of the radius (Figure $1 \mathrm{~B}$ ). It was fixed to a wall in front of the patient (Figure $1 \mathrm{C}$ ) and in perfect alignment by using a plumb line.

Each participant was instructed to memorize the initial neutral position of each movement and repeat it after a submaximal active movement performed by the participant. The investigator wrote the initial and the final position for each movement which was always done in all planes of movement, always following the same order: extension, flexion, right rotation, left rotation, right and left lateral flexion, previously explained to avoid confusing the patients. To obtain a standard for both researcher and subject, a command process was used for each move in the following order:

- "Stay with your neck in a comfortable position" (5 seconds).
- "Perform a: extension and flexion of the head; right and left rotation; lateral flexion to the right and left" (2 seconds for each movement).

- "Return to the start position" (2 seconds for each movement).

- After, the researcher wrote at the coordinate system, for each movement, the initial and final position (2 seconds).

It was used 3 repetitions for every movement, between planes of motion was given a rest period of 2 seconds and between 3 planes of movement the patient was instructed to take the sleep mask off for 20 seconds, to avoid creating a sense of disorientation. The procedure for moving the head and hold it for 2 seconds was used to reduce errors caused by sudden movements of the head. The coordinate system (Figure $1 \mathrm{C}$ ) was preserved for each assessment and was used a new one for each patient. The measurement was taken with the distance between the initial and final positon of the laser projected in the coordinate system (measured in centimeters). So the higher the average distance (greater the error), the greater the neck JPS interference, and the lower the average distance less change in JPS the patient had.

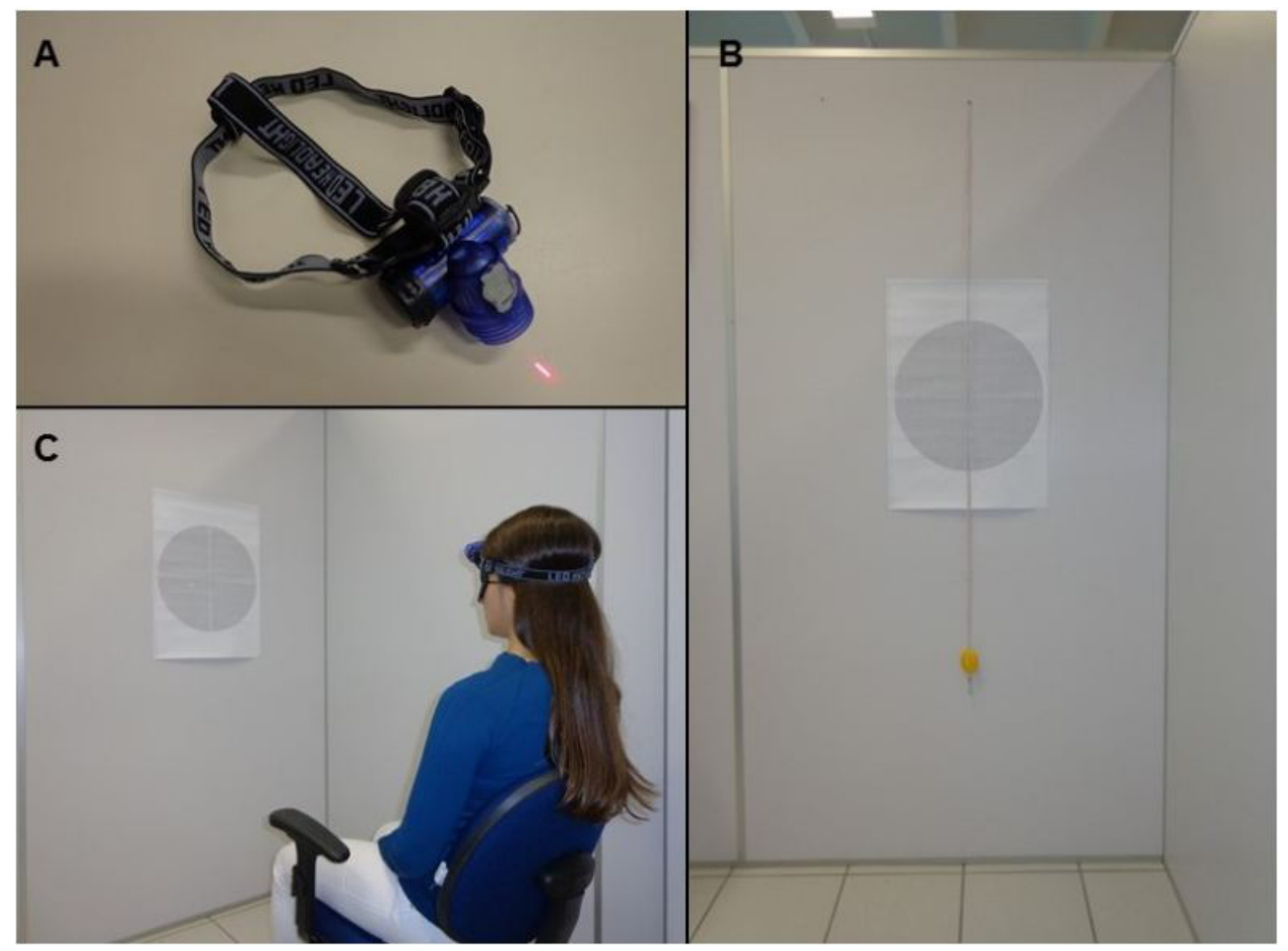

Figure 1. Head Repositioning Acurracy Test. A. Headband with a laser fixed. B. Patient Position. C. Coordinate system. 


\section{Intervention}

All of the patients went through the same clinical evaluation, with imaging and laboratorial analysis when required. Physical examination with specific orthopedic tests, to confirm the inclusion and exclusion criteria according to each patient was performed.

To analyze the cervical spine articular dysfunction both groups underwent a clinical examination including static and dynamic palpation to identify cervical joint dysfunctions which were defined as either an abnormal palpable motion and/or a local tender joint palpable spot, as these criteria are shown to be acceptable and reliable in the literature for the analysis of the cervical spine. ${ }^{(24,30)}$

After the evaluation of one or more joint dysfunctions, the intervention at the MG was a CSM with high-velocity, low-amplitude thrust to the spine held in lateral flexion, with slight rotation and slight extension, with the patient in a seated position (see Figure 2). ${ }^{(18,31,32)}$ This type of CSM is a standard procedure commonly used by chiropractors. ${ }^{(18)}$

For the SG, it was used a validated Sham CSM simulating the sensory experience of a high-velocity, low-amplitude

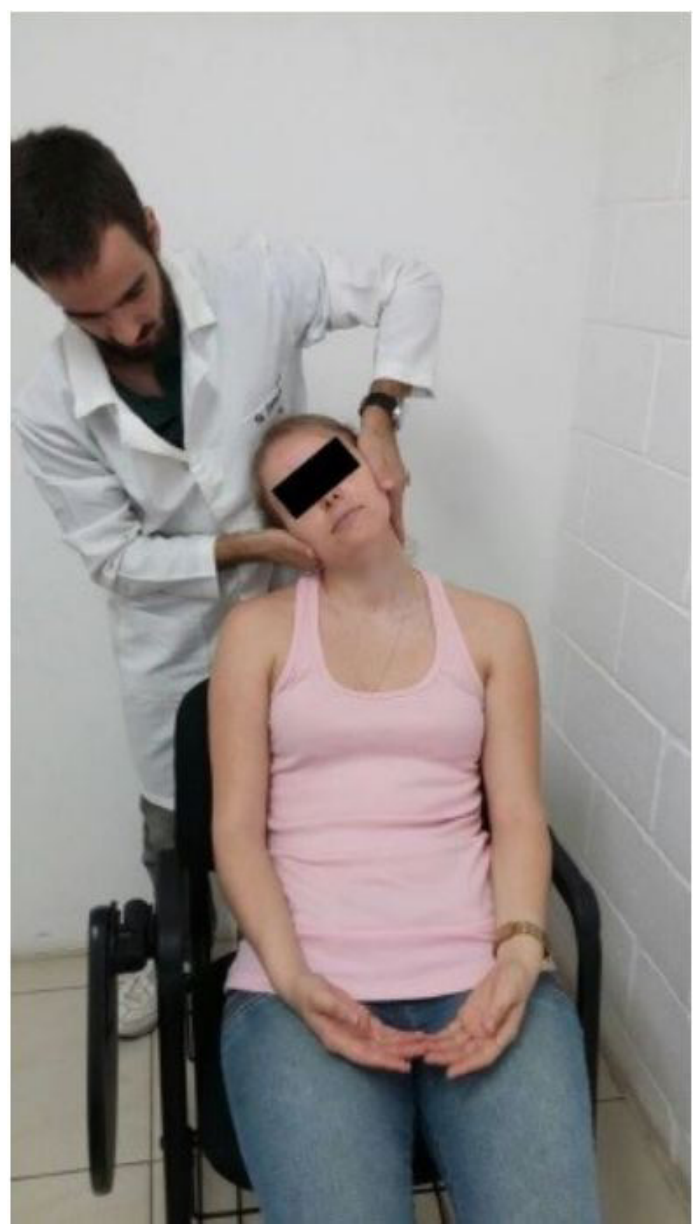

Figure 2. Cervical Spine Manipulation. manipulation procedure with the 4 components of the procedure: touch the region with dysfunction, head positioning, movement and sound with the help of the headpiece table-drop (see Figure 3). ${ }^{(33,34)}$ This procedure proved to be valid immediately after and until 48 hours after the intervention to blind the SG and should be applied in experimental studies to determine whether the treatment results are attributed to the intervention or to a non-specific placebo effect. ${ }^{(35)}$ The figure 4 shows the flowchart of study design.

\section{Statistical analysis}

The statistical analysis was done with the SPSS-22.0 software. Descriptive and Inferential statistics were used. Descriptive statistics consisted of mean, standard deviation, minimum and maximum. To assess data normality, the Shapiro-Wilk test was employed. Inferential statistics consisted

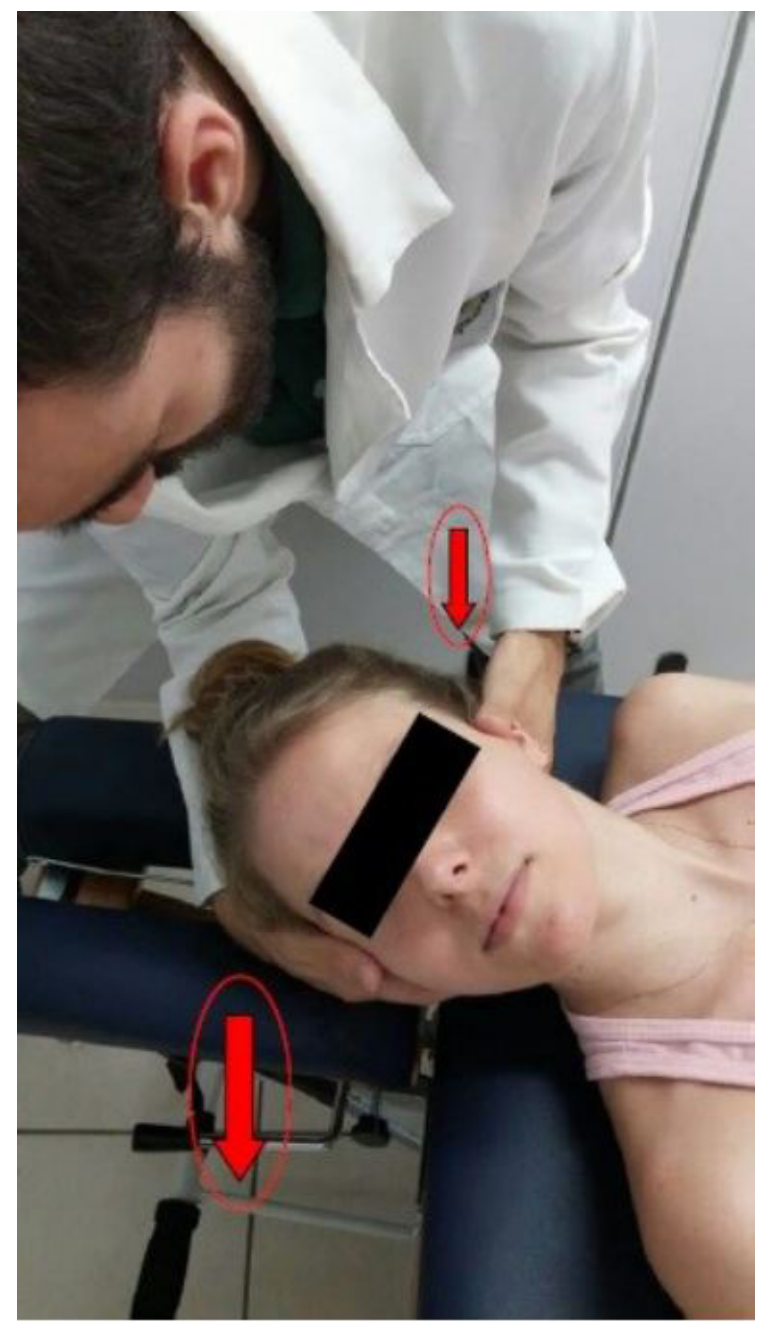

Figure 3. Sham Manipulative Procedure for the Cervical Spine. Small arrow: Chiropractor's hand on the paraspinal area in the restricted vertebra. Big arrow: Chiropractor's forearm as a support for patient head and giving a thrust against the drop headpiece. 
of an Analysis of Variance (ANOVA) for the HRA for pre- and post-intervention 1 and 2 .

\section{RESULTS}

An initial contact was made with 26 patients and 5 was excluded for did not meet the inclusion criteria (NDI $<10 \%$ or vestibular disease) and 21 was included in the study. The allocation ratio was 2:1, 14 for the IG and 7 for SG and all of those completed all the trial (Figure 2).

There were no statistically significant differences inter group for age and height in the pre-treatment assessment $(p<0.05)$, confirming adequate subject similarity. As for weight statistically significant differences were found $(p=0.048)$ between the groups (Table 2 ).

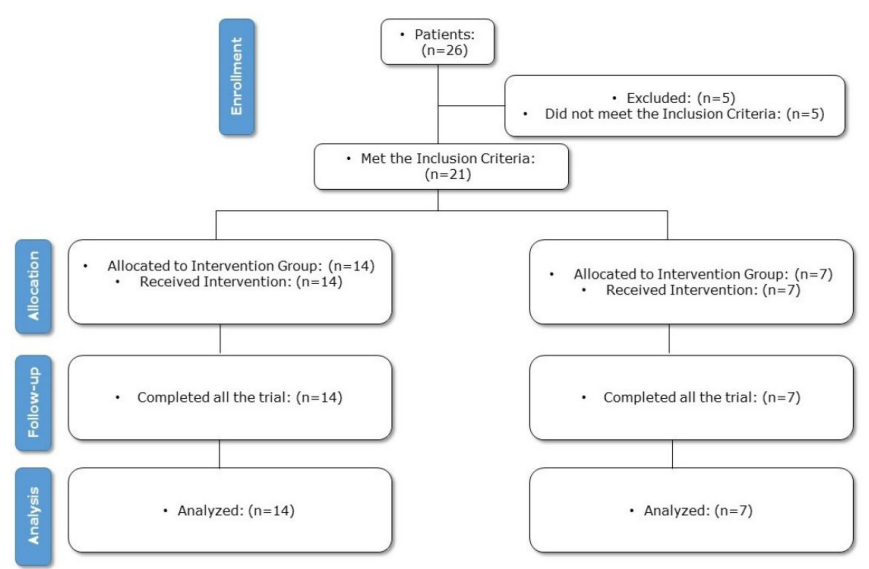

Figure 4. Flowchart of study design

Table 2. Descriptive Analysis

\begin{tabular}{lcc}
\hline \multicolumn{1}{c}{ Sample Data } & Manipulation Group & Sham Group \\
\hline Age (years) & $30.21(11.03)$ & $38.86(17.05)$ \\
Height (meters) & $1.63(0.57)$ & $1.63(0.85)$ \\
Weight (kg) & $65.25(9.83)^{*}$ & $78(18.1)^{*}$ \\
Gender (Female/Male) & $12 \mathrm{~F} \mathrm{e} \mathrm{2} \mathrm{M}$ & $6 \mathrm{~F} \mathrm{e} 1 \mathrm{M}$ \\
\hline
\end{tabular}

*Statistically significant differences $(p<0.05)$

Student T-Test for independent samples

\section{Assessment of Kinesthesia}

For the neck kinesthetic evaluation by the HRA, no significant differences $(p>0.05)$ between pre- and post-intervention 1 and 2 were found using the CSM or a Sham CSM in neither of the movements: flexion/extension, right/left rotation or inclination of the neck (Table 3).

\section{DISCUSSION}

Women are more likely to experience an episode of neck pain than men, also more likely to report symptoms of persistent neck pain and less likely to have a complete resolution of the symptoms of cervical pain and disability. ${ }^{(36)}$ This information is confirmed with the findings of this study that evaluated 18 women and 3 men only (Table 2).

As for age, there is a greater likelihood of symptoms of neck pain in young patients, less than 46 years of age. ${ }^{(20,36)}$ The same information was found in this study, which had a mean age of 34.5 years (Table 2 ). Factors such as body weight and height in previous studies did not presented themselves as important cervical pain incidence predictors. ${ }^{(20)}$

Regarding neck kinesthesia, it was described that it usually has the most significant changes in middle-aged patients (45-65 years old) independently of a history of neck pain. This might be related to muscle spindle deficit in middle-aged patients, which affects the neck JPS error, ${ }^{(28)}$ factor that was not relevant to this work which presented a mean age of 34.5 years (Table 2). As for weight, height and sex, they were not described by Teng et al. ${ }^{(28)}$ as factors that affect the neck JPS. ${ }^{(28)}$ Additionally, Teng et al., Wibault et al. ${ }^{(28,29)}$ says that age as well as gender, body weight, height, body mass index and physical activity were not significantly correlated with the HRA in any of rotational movements. ${ }^{(28,29)}$

To our knowledge, only the study of Rogers ${ }^{(15)}$ intended to evaluate the effects of cervical and thoracic manipulation on the neck kinesthesia in patients with chronic neck pain, as a controlled but not randomized study. ${ }^{(15)}$ And the present study was the first to evaluate the effects of CSM in the cervical kinesthesia, compared to a Sham CSM. Therefore the results

Table 3 - Data for Head Repositioning Acurracy Test (mean (SD)).

\begin{tabular}{|c|c|c|c|c|c|c|}
\hline & \multicolumn{3}{|c|}{ Manipulation Group ( $n=14)$} & \multicolumn{3}{|c|}{ Sham Group (n=7) } \\
\hline & Pre-Intervention & Post-Intervention 1 & Post-Intervention 2 & Pre-Intervention & Post-Intervention 1 & Post-Intervention 2 \\
\hline Extension & $9.91(7.92)$ & 18.55 (9.99) & $7.30(6.20)$ & $14.03(6.67)$ & $12.40(4.83)$ & $10.47(7.60)$ \\
\hline Flexion & $10.21(5.43)$ & $10.67(4.35)$ & $7.74(5.37)$ & $11.73(6.88)$ & $13.32(7.28)$ & $10.33(5.52)$ \\
\hline Right Rotation & $9.81(8.06)$ & $12.30(6.23)$ & $9.03(5.66)$ & $12.61(3.90)$ & $10.95(4.35)$ & $15.84(7.77)$ \\
\hline Left Rotation & $10.51(8.70)$ & $9.66(4.73)$ & $10.99(6.17)$ & $10.41(3.94)$ & $10.66(5.14)$ & $12.67(5.33)$ \\
\hline Right Lateral Flexion** & $7.73(3.90)$ & $11.15(7.46)$ & $8.35(5.30)$ & $9.78(4.48)$ & $13.31(6.39)$ & $12.10(4.41)$ \\
\hline Left Lateral Flexion & $8.84(7.18)$ & $11.71(7.63)$ & $5.80(4.80)$ & $9.50(3.87)$ & $6.55(1.77)$ & $10.46(6.0)$ \\
\hline
\end{tabular}

*Statistically significant differences $(p<0.05)$

** One patient did not perform this movement $(n=13)$

SD: Standard Deviation; Repeated measures ANOVA 
of this study can be discussed with the study Rogers ${ }^{(15)}$ and the studies of Palmgren et al. (12,17) $^{-17}$

There is a parameter, a level of normality, determined in other studies of what would be the error rate of the HRA, in patients with chronic neck pain. ${ }^{(5,27)}$ This level was measured in degrees, by Roren et al. ${ }^{(27)}$, with the same instrument previously proposed by Revel et al. ${ }^{(5)}$ in a study with patients with chronic neck pain at a distance of $90 \mathrm{~cm}$, with unilateral rotation of the neck and has established a mean of $6.3^{\circ}\left(2.4^{\circ}\right)$ for unhealthy patients and $3.6^{\circ}\left(0.8^{\circ}\right)$ for healthy patients. ${ }^{(5,27)}$ For the purposes of this study, this parameter was converted from degrees to centimeters using a simple trigonometry system. Therefore, the average error of the HRA test in patients with chronic neck pain, measured at a $90 \mathrm{~cm}$ distance is $9.96(3.83) \mathrm{cm}$. In addition, Heikkilä \& Wenngren, ${ }^{(16)}$ and Wibault et al. ${ }^{(29)}$ didn't find statistically significant correlation between the HRA with pain or NDI, this is an important factor due to the presence of different levels of pain during the experiment. ${ }^{(16,29)}$

In Palmgren et al. ${ }^{(12)}$ study the scope of practice of chiropractic care (CSM, soft tissue mobilizations, segmental stabilization exercises) was evaluated in regard to pain relief and neck JPS error, and not only the CSM, and it was found a cervical kinesthetic improvement after the chiropractic care. ${ }^{(12)}$ Differently, the study of Palmgren et al. ${ }^{(17)}$ found no statistically significant differences in the neck JPS error with CSM in healthy patients. ${ }^{(17)}$ And according to Rogers ${ }^{(15)}$ cervical and thoracic spine manipulation can have a positive effect on the neck JPS in patients with chronic neck pain. ${ }^{(15)}$ In contrast to the results of this study that didn't show statistically significant differences in the neck kinesthesia after a post-treatment with CSM or a Sham CSM, in any of the groups analyzed or compared (Table 3). Nevertheless, several other studies have proven the effectiveness of chiropractic care and spinal manipulation, in the activation of mechanoreceptors and proprioceptive improvement. ${ }^{(12,15,23,24,37)}$ A possible explanation for the failure to improve neck JPS after a CSM procedure compared with a Sham CSM in patients with chronic neck pain, may be associated with an adaptive reweighting of other sensory modalities' information, like vestibular or cerebellar, which adapted for the inadequacy in the neck sensorimotor that is present in patients with neck dysfunction. ${ }^{(6,24,30)}$ Other reasonable explanation is that the changes in JPS error with the CSM in other studies ${ }^{(12,15)}$ may be due to the placebo effect, since this was the first study to control that variable and no differences was found neither in acute or chronic CSM.

A systematic review concluded that it is more advantageous to classify the patient based on predictors of success in patients with non-specific neck pain. ${ }^{(38)}$ Thus, it is recommended to analyze predictors of success for manipulative treatment, so we can predict which patients will benefit with greater clinical outcome with the cervical spinal manipulation. Among these predictors some of them are bilateral involvement, no radiculopathy and cervical extension less than $45^{\circ} .{ }^{(39,40)}$ So, this way we can evaluate the outcomes of CSM, in an isolated and focused way in the joint dysfunction itself.

\section{CONCLUSIONS}

For the outcomes of the neck JPS there weren't found statistically significant intragroup or intergroup (Manipulation Group and Sham group) differences, but there was a slight trend of improvement in pre-intervention assessment for post-intervention 2, especially for the extension, flexion, right and left rotations movements. However, this may be concealed due the ability of the neck JPS to reweight the hierarchy of sensory information to compensate for inadequacies in any one component.

It is therefore of extreme importance that new studies be made with a high methodological rigor, utilizing clinical prediction rule for cervical spinal manipulation, and also a greater number of patients, with less variability, due to the trend to improve. Still, it is emphasized in this study that the size and variability of the sample, the interval between each treatment session and the use of only one chiropractic technique may have influenced our results.

\section{AUTHOR'S CONTRIBUTION}

IFM developed the project, the methodological and experimental parts and wrote the manuscript. DF was part of the review process of the project and took part on the correction and adjustment of the manuscript. EFM oriented the study as a reviewer for the methodological and experimental parts, and also contributed to the development of the manuscript.

\section{CONFLICTS OF INTEREST}

The authors declare that there are no conflicts of interest.

\section{STATEMENT ON ETHICS}

The study was carried out in the Chiropractic Clinical School of the Feevale University, at Novo Hamburgo, Brasil. Also, this project followed the resolutions of the National Health Council № 466, December 12, 2012, which provides guidelines and standards involving human subjects and it was approved by the university's research ethics committee of the Feevale University ( $\left.n^{\circ} 555.015\right)$. All participants were informed about the procedures, benefits and risks before signing a written informed consent form.

\section{AUTHOR DETAILS}

2. Faculdades Integradas de Taquara, Taquara (RS), Brazil. 3. Feevale University, Novo Hamburgo (RS), Brazil.

\section{REFERENCES}

1. Lent R. Cem Bilhões de Neurônios. 2nd ed. Atheneu, editor. 2010.

2. Machado A. Neuroanatomia Funcional. 2nd ed. Atheneu, editor. São Paulo; 2003.

3. Pinsault N, Vuillerme N. Degradation of cervical joint position sense following muscular fatigue in humans. Spine (Phila Pa 1976). United States; 2010 Feb;35(3):294-297. PMID: 20075783

4. Lee H-M, Liau J-J, Cheng C-K, Tan C-M, Shih J-T. Evaluation of shoulder proprioception following muscle fatigue. Clin Biomech [Internet]. 2003 Nov [cited 2015 Mar 25];18(9):843-847. Available from: http://www. sciencedirect.com/science/article/pii/S0268003303001517 
5. Revel M, Andre-Deshays C, Minguet M. Cervicocephalic kinesthetic sensibility in patients with cervical pain. Arch Phys Med Rehabil. UNITED STATES; 1991 Apr;72(5):288-291. PMID: 2009044

6. Fisher AR, Bacon CJ, Mannion JVH. The effect of cervical spine manipulation on postural sway in patients with nonspecific neck pain. J Manipulative Physiol Ther [Internet]. 2015 Jan [cited 2016 May 16];38(1):65-73. Available from: http://www.sciencedirect.com/ science/article/pii/S0161475414002176 PMID: 25467613

7. Cavanaugh JM, Lu Y, Chen C, Kallakuri S. Pain generation in lumbar and cervical facet joints. J Bone Joint Surg Am. United States; 2006 Apr;88 Suppl 2:63-67. PMID: 16595446

8. Boyd-Clark LC, Briggs C a, Galea MP. Muscle spindle distribution, morphology, and density in longus colli and multifidus muscles of the cervical spine. Spine (Phila Pa 1976). 2002;27(7):694-701. PMID: 11923661

9. Cheng C-H, Chien A, Hsu W-L, Yen L-W, Lin Y-H, Cheng H-YK. Changes of postural control and muscle activation pattern in response to external perturbations after neck flexor fatigue in young subjects with and without chronic neck pain. Gait Posture [Internet]. 2015 Mar [cited 2016 May 19];41(3):801-7. Available from: http://www.sciencedirect. com/science/article/pii/S0966636215000417 PMID: 25759283

10. Taylor HH, Murphy B. The Effects of Spinal Manipulation on Central Integration of Dual Somatosensory Input Observed After Motor Training: A Crossover Study. J Manipulative Physiol Ther. 2010;33(4):261-272. PMID: 20534312

11. Treleaven J. Sensorimotor disturbances in neck disorders affecting postural stability, head and eye movement control. Man Ther [Internet]. 2008 Feb [cited 2015 May 4];13(1):2-11. Available from: http://www. sciencedirect.com/science/article/pii/S1356689X07001191 PMID: 17702636

12. Palmgren PJ, Sandström PJ, Lundqvist FJ, Heikkilä H. Improvement after chiropractic care in cervicocephalic kinesthetic sensibility and subjective pain intensity in patients with nontraumatic chronic neck pain. J Manipulative Physiol Ther [Internet]. 2006 Feb [cited 2015 Jan 20];29(2):100-6. Available from: http://www.sciencedirect.com/ science/article/pii/S0161475405003659 PMID: 16461168

13. Ruhe A, Fejer R, Walker B. Altered postural sway in patients suffering from non-specific neck pain and whiplash associated disorder - A systematic review of the literature. Chiropr Man Therap [Internet]. BioMed Central Ltd; 2011;19(1):13. Available from: http://chiromt.com/ content/19/1/13 PMID: 21609469

14. Phillip Page, Clare Frank RL. Assessment and Treatment of Muscle Imbalance: The Janda Approach. Human Kinetics; 2010.

15. Rogers RG. The effects of spinal manipulation on cervical kinesthesia in patients with chronic neck pain: a pilot study. J Manipulative Physiol Ther. UNITED STATES; 1997 Feb;20(2):80-85. PMID: 9046455

16. Heikkilä H V., Wenngren B-I. Cervicocephalic kinesthetic sensibility, active range of cervical motion, and oculomotor function in patients with whiplash injury. Arch Phys Med Rehabil [Internet]. 1998 Sep [cited 2015 Apr 8];79(9):1089-1094. Available from: http://www.sciencedirect.com/ science/article/pii/S0003999398901769

17. Palmgren PJ, Lindeberg A, Nath S, Heikkilä H. Head Repositioning Accuracy and Posturography Related to Cervical Facet Nerve Blockade and Spinal Manipulative Therapy in Healthy Volunteers: A Time Series Study. J Manipulative Physiol Ther [Internet]. 2009 Mar [cited 2015 Apr 8];32(3):193-202. Available from: http://www.sciencedirect.com/ science/article/pii/S0161475409000499

18. MIRANDA I, FACCHINI D, MANFIO E. Influence of the cervical spine manipulation in the neck disability index in patients with chronic neck pain : A preliminary study Influência da manipulação articular cervical no índice de incapacidade do pescoço em pacientes com dor cervical crônica : Um. Man Ther Posturology Rehabil J. 2015;13(August):1-5.
19. Bryans $R$, Decina $P$, Descarreaux $M$, Duranleau $M$, Marcoux $H$, Potter B, Ruegg RP, Shaw L, Watkin R, White E. Evidence-based guidelines for the chiropractic treatment of adults with neck pain. J Manipulative Physiol Ther [Internet]. 2014 Jan [cited 2015 Jan 11];37(1):42-63. Available from: http://www.sciencedirect.com/science/article/pii/ S0161475413002376 PMID: 24262386

20. Hoy DG, Protani M, De R, Buchbinder R. The epidemiology of neck pain. Best Pract Res Clin Rheumatol [Internet]. 2010 Dec [cited 2015 Jan 28];24(6):783-92. Available from: http://www.sciencedirect.com/ science/article/pii/S1521694211000246 PMID: 21665126

21. Borghouts JA., Koes BW, Vondeling H, Bouter LM. Cost-of-illness of neck pain in The Netherlands in 1996. Pain [Internet]. 1999 Apr [cited 2015 Feb 10];80(3):629-636. Available from: http://www.sciencedirect.com/ science/article/pii/S0304395998002681

22. National Board of Chiropractic Examiners. New Information and Trends in Chiropractic Practice 1991 through 2014. 2015.

23. Haavik $\mathrm{H}$, Murphy B. The role of spinal manipulation in addressing disordered sensorimotor integration and altered motor control. J Electromyogr Kinesiol [Internet]. 2012 Oct [cited 2015 Mar 24];22(5):768-76. Available from: http://www.sciencedirect.com/ science/article/pii/S1050641112000430 PMID: 22483612

24. Haavik H, Murphy B. Subclinical neck pain and the effects of cervical manipulation on elbow joint position sense. J Manipulative Physiol Ther [Internet]. $2011 \mathrm{Feb}$ [cited $2015 \mathrm{Feb} 10] ; 34(2): 88-97$. Available from: http://www.sciencedirect.com/science/article/pii/S0161475410003611 PMID: 21334540

25. Paulus I, Brumagne S. Altered interpretation of neck proprioceptive signals in persons with subclinical recurrent neck pain. J Rehabil Med. Sweden; 2008 Jun;40(6):426-432. PMID: 18509556

26. Pinsault N, Vuillerme N, Pavan P. Cervicocephalic relocation test to the neutral head position: assessment in bilateral labyrinthine-defective and chronic, nontraumatic neck pain patients. Arch Phys Med Rehabil. United States; 2008 Dec;89(12):2375-2378. PMID: 19061750

27. Roren A, Mayoux-Benhamou M-A, Fayad F, Poiraudeau S, Lantz D, Revel M. Comparison of visual and ultrasound based techniques to measure head repositioning in healthy and neck-pain subjects. Man Ther [Internet]. 2009 Jun [cited 2015 Mar 29];14(3):270-7. Available from: http://www.sciencedirect.com/science/article/pii/S1356689X0800057X PMID: 18514016

28. Teng C-C, Chai H, Lai D-M, Wang S-F. Cervicocephalic kinesthetic sensibility in young and middle-aged adults with or without a history of mild neck pain. Man Ther. Scotland; 2007 Feb;12(1):22-28. PMID: 16777468

29. Wibault J, Vaillant J, Vuillerme N, Dedering Å, Peolsson A. Using the cervical range of motion (CROM) device to assess head repositioning accuracy in individuals with cervical radiculopathy in comparison to neck- healthy individuals. Man Ther [Internet]. 2013 Oct [cited 2015 Mar 15];18(5):403-409. Available from: http://www.sciencedirect.com/ science/article/pii/S1356689X13000337

30. Daligadu J, Haavik H, Yielder PC, Baarbe J, Murphy B. Alterations in cortical and cerebellar motor processing in subclinical neck pain patients following spinal manipulation. J Manipulative Physiol Ther [Internet]. 2013 Oct [cited 2015 Feb 10];36(8):527-37. Available from: http:// www.sciencedirect.com/science/article/pii/S0161475413002030 PMID: 24035521

31. Saraiva MC. Manual de técnicas quiropraticas. 2nd ed. Novo Hamburgo, Brazil: Feevale University; 2006.

32. Palmer College of Chiropractic Technique Department. PALMER COLLEGE OF CHIROPRACTIC. 1998. 
33. Vernon H, MacAdam K, Marshall V, Pion M, Sadowska M. Validation of a sham manipulative procedure for the cervical spine for use in clinical trials. J Manipulative Physiol Ther [Internet]. 2005 Jan [cited 2015 Feb 10];28(9):662-6. Available from: http://www.sciencedirect.com/ science/article/pii/S0161475405003015 PMID: 16326235

34. Vernon HT, Triano JJ, Ross JK, Tran SK, Soave DM, Dinulos MD. Validation of a novel sham cervical manipulation procedure. Spine J [Internet]. 2012 Nov [cited 2015 Jan 18];12(11):1021-8. Available from: http:// www.sciencedirect.com/science/article/pii/S1529943012012855 PMID: 23158966

35. Vernon H, Triano JT, Soave D, Dinulos M, Ross K, Tran S. Retention of blinding at follow-up in a randomized clinical study using a sham-control cervical manipulation procedure for neck pain: secondary analyses from a randomized clinical study. J Manipulative Physiol Ther [Internet]. 2013 Oct [cited 2015 Jan 18];36(8):522-6. Available from: http://www. sciencedirect.com/science/article/pii/S0161475413001991 PMID: 24011656

36. Côté P, Cassidy JD, Carroll LJ, Kristman V. The annual incidence and course of neck pain in the general population: a population-based cohort study. Pain [Internet]. 2004 Dec [cited 2015 Jan 10];112(3):267-73. Available from: http://www.sciencedirect.com/science/article/pii/ S0304395904004269 PMID: 15561381
37. Pickar JG. Neurophysiological effects of spinal manipulation. Spine J. United States; 2002;2(5):357-371. PMID: 14589467

38. Schellingerhout JM, Verhagen AP, Heymans MW, Pool JJM, Vonk F, Koes BW, Wilhelmina de Vet HC. Which subgroups of patients with non-specific neck pain are more likely to benefit from spinal manipulation therapy, physiotherapy, or usual care? Pain. Netherlands; 2008 Oct;139(3):670680. PMID: 18774225

39. Tseng Y-L, Wang WTJ, Chen W-Y, Hou T-J, Chen T-C, Lieu F-K. Predictors for the immediate responders to cervical manipulation in patients with neck pain. Man Ther [Internet]. 2006 Nov [cited 2015 Mar 2];11(4):306-15. Available from: http://www.sciencedirect.com/science/article/pii/ S1356689X05001244 PMID: 16380287

40. Saavedra-Hernández M, Ssavedra-Hernández M, Castro-Sánchez AM, Fernández-de-Las-Peñas C, Cleland JA, Ortega-Santiago R, Arroyo-Morales $M$. Predictors for identifying patients with mechanical neck pain who are likely to achieve short-term success with manipulative interventions directed at the cervical and thoracic spine. J Manipulative Physiol Ther [Internet]. 2011 Jan [cited 2014 Dec 19];34(3):144-52. Available from: http://www.sciencedirect.com/science/article/pii/S0161475411000406 PMID: 21492749' 